\title{
Educação Infantil e Cidade Educadora: pelas representações do discurso documental e das narrativas
}

\author{
Early Childhood Education and the Educating City: by \\ representations of documentary discourse and narratives
}

Educación Infantil y Ciudad Educadora: por las representaciones de lo discurso documental y de las narrativas

\author{
SUELI PEREIRA DONATO ${ }^{\mathrm{a}}$ iD \\ JAQUELINE SALANEK De OLIVEIRA NAGEL ${ }^{b}(\mathbb{D})$
}

\section{Resumo}

Este artigo focaliza a educação infantil na interface com a cidade educadora. Para tanto, buscouse, neste estudo, analisar o discurso presente na Carta das Cidades Educadoras, produzido pela Associação Internacional das Cidades Educadoras (AICE) e sua relação com o da Base Nacional Comum Curricular (BNCC) para a Educação Infantil, e do Programa Linhas do Conhecimento da Secretaria Municipal da Educação de Curitiba-PR. O estudo encontra guarida na Teoria das Representações (MOSCOVICI, 2015; JODELET, 2001), em articulação com os estudos de Jodelet (2007), Souza (2011), Teibel e Andrade (2017) sobre análises textuais. A investigação relaciona a análise do discurso do documento "Carta das Cidades Educadoras" (AICE), a BNCC e do Programa Linhas do Conhecimento. O documento foi processado pelo software Iramuteq (RATINAUD, 2009), que permitiu a realização da análise de Classificação Hierárquica Descendente (CHD), favorecendo a identificação de diferentes classes no texto documento com o discurso da Base Nacional Comum Curricular da Educação Infantil e o Programa Linhas do Conhecimento. O resultado revelou que as proposições presentes nos documentos estão ancoradas em princípios enaltecidos no discurso da Carta das Cidades Educadoras. Evidenciou, ainda, o grande desafio para sensibilizar todos os habitantes da cidade para que seus olhares sejam voltados ao processo educacional que existe e acontece na cidade.

Palavras-chave: Carta das Cidades Educadoras. Educação Infantil. Narrativas. Representações Sociais.

\section{Abstract}

This article focuses on early childhood education in the interface with the educating city. Therefore, it was sought, in this study, to analyze the discourse from the Educating Cities Letter,

a Centro Universitário Internacional Uninter, Curitiba, PR, Brasil. Doutora em Educação, e-mail: sueli.donato@gmail.com b Pontifícia Universidade Católica do Paraná, Curitiba, PR, Brasil. Mestre em Educação, e-mail:
jaquenagel@gmail.com 
produced by the International Association of Educating Cities (AICE) and its relationship with the one from the Common National Curricular Base (CNCB) for Early Childhood Education, and the Lines of Knowledge Program of the Municipal Education Secretariat of Curitiba-PR. The study finds support in the Theory of Representations (MOSCOVICI, 2015; JODELET, 2001), in conjunction with the studies of Jodelet (2007), Souza (2011), Teibel and Andrade (2017) on textual analysis. The investigation relates the discoursive analysis of the document "Educating Cities Letter" (AICE of Educating Cities) (AICE), CNCB and the Lines of Knowledge Program. The document was processed by the Iramuteq software (RATINAUD, 2009), which allowed the analysis of Descending Hierarchical Classification (CHD), favoring the identification of different classes in the text document with the discourse of the Common National Curricular Base of Early Childhood Education and the Program Knowledge Lines. The result revealed that the propositions present in the documents are anchored in principles highlighted in the discourse of the Educating Cities Letter. It also evidenced the great challenge to sensitize all the inhabitants of the city so that their eyes are turned to the educational process that exists and happens in the city.

Keywords: Educating Cities Letter. Early Childhood education. Narratives. Social Representations.

\section{Resumen}

Este artículo se centra en la educación infantil en la interfaz con la ciudad educadora. Por lo tanto, se buscó, en este estudio, analizar el discurso de la Carta de Ciudades Educadoras, producida por la Asociación Internacional de Ciudades Educadoras (AICE) y su relación con el discurso de la Base Curricular Nacional Común (BNCC) para la Educación de la Primera Infancia y el Programa de Líneas de Conocimiento de la Secretaría Municipal de Educación de Curitiba-PR. El estudio encuentra apoyo en la Teoría de las representaciones (MOSCOVICI, 2015; JODELET, 2001), junto con los estudios de Jodelet (2007), Souza (2011), Teibel y Andrade (2017) sobre análisis textual. La investigación relaciona el análisis discursivo del documento "Carta de Ciudades Educadoras" (AICE), BNCC y el Programa Líneas de Conocimiento. El documento fue procesado por el software Iramuteq (RATINAUD, 2009), que permitió el análisis de la Clasificación Jerárquica Descendente (CHD), favoreciendo la identificación de diferentes clases en el documento de texto con el discurso de la Base Curricular Nacional Común de Educación Infantil y las líneas de conocimiento del programa. El resultado reveló que las proposiciones presentes en los documentos están ancladas en principios destacados en el discurso de la Carta de Ciudades Educadoras. También evidenció el gran desafio de sensibilizar a todos los habitantes de la ciudad para que sus ojos se vuelvan hacia el proceso educativo que existe y sucede en la ciudad.

Palabras clave: Carta de Ciudades Educadoras. Educación infantil. Narrativas Representaciones sociales.

A Cidade se faz educativa pela necessidade de educar, de aprender, de ensinar, de conhecer, de criar, de sonhar, de imaginar [...] (FREIRE, 2001, p.13).

Introdução 
A Cidade Educadora pode ser entendida como "[...] uma cidade que se relaciona com o seu meio envolvente, outros centros urbanos do seu território e cidades de outros países. O seu objetivo permanente será o de aprender, trocar, partilhar e, por consequência, enriquecer a vida dos seus habitantes" (AICE, 2004, p. 1). A formação de todos os seus habitantes ocorre ao longo da vida, seja ela de crianças, jovens, adultos e idosos. A educação não se resume apenas àquela que acontece dentro dos muros da escola ou entre as quatro paredes das salas de aula, mas se dá na vida cotidiana, escrita em um grande livro, como descrita por Carbonell (2002, p. 103):

[...] um livro aberto que é preciso aprender a olhar e a interpretar e que é um excelente laboratório para trabalhar o processo de trânsito da anedota à categoria, do concreto ao abstrato, das noções isoladas à sua sistematização, da informação ao conhecimento.

Ao pressupor a educação integral e inclusiva dos habitantes de uma cidade, destacam-se, aqui, as palavras de Zitkoski (2006, p. 12), que ressalta a ampliação do conceito de educação em uma Cidade Educadora, porque essa "[...]compreende todos os processos de formação da pessoa humana na integralidade de suas dimensões, ou seja, a educação está relacionada com a cultura, lazer, política, trabalho, vida social, cidadania e/ou participação social”.

Evidencia-se, portanto, com base em Lefebvre (2001, p. 118), a potencialidade educativa de uma cidade e sua amplitude de espaços educativos, como “[...] lugar de encontro, prioridade do valor do uso, inscrição no espaço de um tempo promovido à posição de supremo bem entre os bens [...]”, e assim sendo, as ruas, as praças, os museus, os teatros, os parques, as bibliotecas, os cinemas, entre outros espaços urbanos, culturais e de lazer, que se caracterizam como possibilidades de encontro e interação, experiências e aprendizagens ao serem intencionalmente planejados pelos professores, de acordo com as propostas pedagógicas e currículos locais.

Sob essa perspectiva, ao considerarmos que a "[...] a criança, centro do planejamento curricular, é sujeito histórico e de direitos que, nas interações, relações e práticas cotidianas que vivencia, constrói sua identidade pessoal e coletiva [...]" (BRASIL, 2009), é compreensível que avancemos na garantia do direito da criança à cidade e na efetivação de práticas pedagógicas que possam e necessitem se estender 
a outros espaços, sejam eles culturais ou de encontro com e na natureza. O texto da Base Nacional Comum Curricular (BRASIL, 2017b) destaca a Educação Infantil como "[...] a primeira separação das crianças dos seus vínculos afetivos familiares para se incorporarem a uma situação de socialização estruturada", que precisa ser planejada e refletida pelos profissionais envolvidos, pois como Nóvoa (2017, p. 1127) indica, “[...] ser professor não é apenas lidar com o conhecimento, é lidar com o conhecimento em situações de relação humana”.

Essas ponderações convidam-nos a olhar e refletir criticamente sobre a escola contemporânea, espaço legalmente constituído de socialização e educação das crianças em parceria com a família. Dependendo da concepção teóricometodológica que sustenta as práticas pedagógicas realizada, desenha um lócus, que fechado em seus muros, limita-se a práticas desvinculadas das possibilidades educativas presentes na cidade e, com efeito, minimiza o potencial das oportunidades de relações estabelecidas entre a criança e o seu entorno social como fonte de desenvolvimento (VYGOTSKY, 1991), além de restringir uma formação pela cidadania ativa.

Uma Cidade Educadora não se constitui apenas por decisões políticas governamentais ou ações da sociedade civil, pois se instaura como compromisso partilhado entre eles (BELLOT, 2013), porquanto sua interdependência está diretamente ligada ao ritmo, à história, às especificidades e ao projeto político de cada uma delas. Tal interdependência estabelecida denota particularmente que a Cidade Educadora cumpra suas funções de cidadania inclusiva, coesão, sustentabilidade, educação para a paz e equidade (BELLOT, 2013). Além das funções educativas tradicionais, destacamos a necessidade de atenção com relação à responsabilidade dos governos locais, no sentido de que nas escolas se potencialize e promova o desenvolvimento das capacidades educativas que a cidade abarca, incorporando ao seu projeto de governo os princípios da Cidade Educadora (POZO, 2013), expressos na Carta das Cidades Educadoras (2004)ํ.

\footnotetext{
${ }^{1}$ Segundo Gadotti (2006), o conceito de Cidade Educadora consolidou-se no início da década de 1990, em Barcelona, na Espanha, onde se realizou o primeiro Congresso Internacional das Cidades Educadoras. Esse Congresso aprovou, em novembro de 1990, uma carta de princípios básicos que caracterizam uma cidade que educa e que foi revista no III Congresso Internacional em Bolonha (1994) e no de Génova (2004).
} 
Nesse viés, incorporando o direito da criança à cidade e a efetivação de práticas pedagógicas, estas podem e devem se estender a outros espaços fora da escola, alicerçadas no que está posto na Base Nacional Comum Curricular — BNCC (BRASIL, 2017b). O estudo objetiva analisar os sentidos dos discursos presentes ou ausentes, comparando o documento "Carta das Cidades Educadoras" (AICE, 2004), a BNCC para a Educação Infantil e a proposta do Programa Linhas do Conhecimento, da Secretaria Municipal da Educação de Curitiba (SME). Trata-se, portanto, de um estudo que estabelece aproximações teóricas entre o campo da abordagem de discursos como narrativas documentais e o da Teoria das Representações Sociais (TRS) por reconhecermos, apoiadas em Jodelet (2007), as imbricações que se estabelecem entre RS e intervenção no tocante ao conhecimento do cotidiano, mergulhado em contextos culturais e sociais presentes nas vivências mediadas pela interação e práticas discursivas.

\section{A educação infantil na perspectiva de} uma cidade educadora

A educação infantil, primeira etapa da educação básica, tem como principais documentos normativos e orientadores a Lei de Diretrizes de Bases da Educação Nacional (LDBEN) - Lei n. 9 9.394/1996, os Parâmetros Nacionais de Qualidade para a Educação Infantil (BRASIL, 2006), as Diretrizes Curriculares Nacionais para a Educação Infantil (DCNEI), revisadas em 2009, e a Base Nacional Comum Curricular (BNCC), implantada pela Resolução CNE/CP n. 02/2017 (BRASIL, 2017a).

Quaisquer documentos normativos e orientadores por si não efetivam mudanças na prática docente. Esses documentos, em parte, regulam a política educacional estabelecida para que atinja a prática dos educadores, na educação dos bebês, crianças bem pequenas e crianças pequenas ${ }^{2}$. No entanto, de acordo com Ball, Maguire e Braun (2016, p. 13), o processo que envolve a política educacional abrange “[...] processos discursivos que são complexamente configurados,

\footnotetext{
${ }^{2}$ Segundo a BNCC (2017), “[...] ao apresentar os objetivos de desenvolvimento e aprendizagem para a educação infantil, organiza-se em três grupos por faixa etária que correspondem a: bebês (zero a 1 ano e 6 meses); crianças bem pequenas ( 1 ano e 7 meses a 3 anos e 11 meses) e crianças pequenas ( 4 anos a 5 anos e 11 meses)" (BRASIL, 2017, p. 44).
} 
contextualmente mediados e institucionalmente prestados. A política é feita pelos e para os professores; eles são atores e sujeitos, sujeitos e objetos da política”, em que se pode concluir que os documentos normatizam a política, mas as mudanças resultam de uma reflexão sobre a prática, pela tomada de consciência do profissional que (co)conduz o processo educativo.

As Diretrizes Curriculares Nacionais (2009) para a Educação Infantil orientam para que o trabalho desenvolvido nesta etapa de ensino ocorra na confluência de dois eixos norteadores: das interações e do brincar. Com efeito, prezar pelo trabalho pedagógico condizente com as especificidades e singularidades de crianças de zero a cinco anos de idade instiga a repensar os espaços, tempos e materiais a elas propiciados a partir da intencionalidade dos professores, que possam viabilizar experiências e aprendizagens apropriadas para o seu desenvolvimento.

A garantia do direito de bebês, crianças bem pequenas e crianças pequenas de vivenciarem a diversidade de experiências na educação infantil é apontada no artigo $9^{\circ}$ das DCNEI (2009), nomeadamente em dois incisos. No inciso I, no que dispõe que as práticas pedagógicas devem garantir “[...] o conhecimento de si e do mundo por meio da ampliação de experiências sensoriais, expressivas, corporais que possibilitem movimentação ampla, expressão da individualidade e respeito pelos ritmos e desejos das crianças", e no inciso IX, ao reforçar a importância de promover "[...] o relacionamento e a interação das crianças com diversificadas manifestações de música, artes plásticas e gráficas, cinema, fotografia, dança, teatro, poesia e literatura” (BRASIL, 2009).

Tais orientações desafiam-nos a pensar em uma educação infantil que extrapole os muros das instituições educativas, considerando as condições para a aprendizagem, materialidades, tempos, agrupamentos e espaços. Desse modo, o entorno, o bairro e os espaços extraescolares devem se constituir em territórios pedagógicos a serem conquistados pelas crianças desde o início do seu processo de escolarização. A esse respeito, partilhamos do entendimento de Tonucci (1997) ao expressar o quanto as crianças são competentes e podem ser inseridas em processos de participação democrática, situações nas quais elas possam expressar seus desejos 
e ideias a partir do seu ponto de vista e, assim, contribuírem para a construção de cidades cada vez mais humanizadas e acolhedoras.

Ao apresentar a importância dessa participação e qualificar seus efeitos como pedagogia inovadora, Carbonell (2016, p. 13) afirma que

[...] a incorporação da experiência de vida e extraescolar à educação formal" tem por objetivo o de "[...] educar o olhar, as inteligências múltiplas e as diversas linguagens comunicativas, para descobrir, explorar, perceber e sentir o que acontece na cidade de maneira explícita e oculta (p. $14)$.

Os pressupostos apresentados convergem com o conceito de Cidade Educadora, pelo qual o potencial educativo da cidade se dá “[...] pelo conjunto de relações sociais, políticas e culturais que perpassam a vida cotidiana de seus cidadãos e cidadãs, quanto pela densidade de seus territórios físicos — arquitetônicos, históricos, naturais” (MOLL, 2013, p. 215).

Zainko (1997, p. 105) corrobora na tessitura do conceito de Cidade Educadora ao esclarecer que esta se refere “[...] também e, primordialmente sociedade, a realidades e utopias. A utopia de uma menos desigual, mais humana, mais justa, mais livre e solidária", na qual se valoriza a participação ativa dos seus habitantes, diante dos desafios impostos pela globalização dos processos econômicos e sociais e, neste contexto, crianças e jovens assumem papel de protagonistas da vida social e da cidade (AICE, 2004).

Um dos grandes desafios à educação, relacionado ao desenvolvimento de uma sociedade mais participativa e democrática, segundo Zitkoski (2006, p. 17), é o de " [...] desencadear o processo de empoderamento dos cidadãos e das cidadãs para que possam ir construindo uma nova cultura em relação aos processos políticos e sociais em termos de organização social e de controle da coisa pública como um bem de todos", porquanto, em uma Cidade Educadora necessariamente se valoriza a participação democrática de todos os cidadãos, o diálogo, a cooperação e o respeito mútuo (AICE, 2004).

Tal participação, na visão de Tonucci (2005, p. 20), começa nas instituições de educação infantil, tendo em vista que a criança “[...] é uma pessoa titular de direitos, com uma maneira própria de pensar e de ver o mundo”. A concepção de criança protagonista apontada pelo autor relaciona-se às DCNEI (2009), ao art. $4^{\circ}$, quando este expressa que "[...] a criança, centro do planejamento curricular, é 
sujeito histórico e de direitos que, nas interações, relações e práticas cotidianas que vivencia, constrói sua identidade pessoal e coletiva [...]”" (BRASIL, 2009).

Nessa seara política, na qual se vislumbra a educação, desde a educação infantil como ato político (FREIRE, 1991), a ação educativa exige que esta propicie interações entre todos que convivem no espaço urbano, em diferentes instâncias e contextos, com o intuito de estimular o crescimento e desenvolver potencialidades, por meio de projetos individuais e coletivos, como alude Pozo (2013).

Sobre as interações em diferentes instâncias e contextos, Nóvoa (2017, p. 1121), ao discorrer sobre a proposta de formação de professores, partindo do entendimento de que a escola assume pilares centrais, argumenta que "o conhecimento e a mobilidade social" apontam uma tendência em relação ao contexto educacional, qual seja, a abertura da escola ao espaço público da educação, o que "[...] implica uma participação mais ampla da sociedade nas questões educativas (famílias, associações, movimentos sociais, eleitos locais, etc.)".

Para tanto, esse autor ressalta a necessidade da reconstrução de laços e vínculos, rompidos a partir do momento em que a escola se fechou dentro dela, e indica como facilitadores a difusão digital e a mobilização de tempos e dinâmicas "fora dos muros da escola", para que ocorram mudanças na escola e em sua relação com a sociedade. Nesse sentido, cabe ao educador do presente ouvir novas vozes e celebrar novos vínculos com a sociedade, nomeadamente as vozes da comunidade, traduzidas nas vozes da cidade. Para tal, recorremos para as três dimensões propostas por Bernet (1997, p. 17) na defesa da relação educação com a cidade, no sentido de "[...] aprender em la ciudad (La ciudad como contenedor de recursos educativos); Aprender de la ciudad (La ciudad como agente de educación); Aprender em la ciudad (La ciudad como contenedor de recursos educativos)".

Sob outra perspectiva, Paulo Freire evidencia que a cidade educadora também é educanda, pois “[...] muito de sua tarefa educativa implica a nossa posição política e, obviamente, a maneira como exerçamos o poder na Cidade e o sonho ou a utopia de que embebamos a política, a serviço de que e de quem a fazemos" (FREIRE, 2001, p. 13). A utopia destacada por Freire (2001) é balizada pelos objetivos e pressupostos de uma Cidade Educadora, descritos na Carta das Cidades 
Educadoras (AICE, 2004), documento assinado por representantes de todas as cidades representadas no $1^{\circ}$ Congresso Internacional de Cidades Educadoras, realizado em Barcelona (Espanha), em novembro de 1990, revisitado e atualizado nas edições do congressos subsequentes (1994; 2004), a fim de se adaptar aos novos desafios e às necessidades sociais.

A Carta organizada apresenta o preâmbulo e contempla 20 princípios. Define a Cidade Educadora como uma instância com personalidade própria, que se relaciona ao seu meio e a outros territórios nacionais e internacionais e construída considerando a Declaração Universal dos Direitos Humanos (1948), o Pacto Internacional dos Direitos Econômicos, Sociais e Culturais (1966), a Declaração Mundial da Educação para Todos (1990), a Convenção da Cúpula Mundial para a Infância (1990) e a Declaração Universal sobre Diversidade Cultural (2001).

O objetivo permanente de uma Cidade Educadora "[...] será o de aprender, trocar, partilhar e, por consequência, enriquecer a vida dos seus habitantes”. Essa cidade deve promover a educação ao longo da vida de seus habitantes, no entanto crianças e jovens devem ser sua prioridade (AICE, 2004). Segundo o documento dessa sociedade internacional, a Cidade Educadora tem como uma de suas principais funções a produção de “[...] uma verdadeira fusão da etapa educativa formal com a vida adulta, dos recursos e do potencial formativo da cidade com o normal desenvolvimento do sistema educativo, laboral e social".

O direito e esse tipo de cidade, preparada para as crianças e para jovens, adultos e idosos, remete-nos a Lefebvre (2001) ao descrevê-la como um lugar de encontro, de necessidades opostas e complementares e de formação, visto que, em suas palavras, "O ser humano tem também a necessidade de acumular energias e a necessidade de gastá-las, e mesmo de desperdiçá-las no jogo. Tem necessidade de ver, de ouvir, de tocar, de degustar, e a necessidade de reunir essas percepções num 'mundo"' (LEFEBVRE, 2001, p. 105).

Na perspectiva de uma Cidade Educadora, Curitiba, signatária da Carta das Cidades Educadoras desde novembro de 2018, busca efetivar ações integradas com instituições parceiras (parques, museus, teatro, universidades, empresas, etc.), com a intenção de ampliar as vivências das crianças da educação infantil, dos estudantes do 
ensino fundamental e dos profissionais da educação, tanto no aspecto territorial quanto cultural. A partir do Programa Linhas do Conhecimento, a cidade, em sua proposta, é concebida como um grande laboratório de aprendizagens e que "[...] ao fazer uso do espaço da cidade para educar e promover o processo de ensinoaprendizagem realiza-se um processo contínuo de construção e de transformação social” (ALVES; BRANDENBURG, 2018, p. 24), que podem e ocorrem desde a educação infantil.

\section{A base documental: BNCC e o Caderno Linhas do Conhecimento}

A Base Nacional Comum Curricular, implantada em 2017, enfatiza que o objetivo da educação infantil é o de "[...] ampliar o universo de experiências, conhecimentos e habilidades dessas crianças, diversificando e consolidando novas aprendizagens [...]" (BRASIL, 2017b, p. 36).

No âmbito da educação infantil ofertada nos Centros Municipais de Educação Infantil no município de Curitiba, destacamos como uma das possibilidades de ampliação do universo de experiências das crianças o Programa Linhas do Conhecimento, o qual tem “[...] como ponto de partida as propostas lúdicas, que contribuem para ampliação cultural a partir do currículo, para as interlocuções sociais e para as práticas pedagógicas dos professores, na intenção de promover a pertença dos sujeitos aos espaços urbanos" (CURITIBA, 2018b, p. 12-13).

O Programa Linhas do Conhecimento tem suas raízes na década de 1990, quando em comemoração aos 300 anos da cidade de Curitiba, foi inaugurada a "Linha do Pinhão". Na época, essa "Linha", demarcada em algumas calçadas centrais da cidade, tinha o "[...] o objetivo de conduzir as crianças pelos pontos turísticos e históricos que marcam a memória curitibana” (CURITIBA, 2019, p. 14). 
O Programa Linhas do Conhecimento, parte do plano ${ }^{3}$ de governo municipal, envolvia áreas como artes visuais, literatura, música, teatro, patrimônio, fotografia, jogos e brincadeiras, tendo como seu pilar o de contribuir para que fosse conhecida "[...] a cidade, sua história, sua identidade e, por meio de visitas, [...aprendidas] as primeiras noções de educação musical, teatro, literatura e fotografia (CURITIBA, 2019, p. 15).

Na gestão municipal de 2017-2020, o Programa Linhas do Conhecimento foi retomado no programa de governo, porém integrado no "Viva Curitiba Cidadã", programa maior e intersetorial no qual diversas secretarias e órgãos do governo deviam se articular, de modo a "[...] promover acesso aos direitos básicos de cidadania, por meio de ações intersetoriais voltadas ao pleno desenvolvimento dos indivíduos e a integração com o meio, valorizando a diversidade de expressões e considerando a sustentabilidade de recursos" (CURITIBA, 2018c, p. 1).

O Programa Linhas do Conhecimento propõe que as propostas lúdicas, aulas de campo ou atividades culturais e esportivas na cidade, de acordo com as especificidades da etapa de ensino ou modalidade, sejam desenvolvidas em consonância com o Currículo da Educação Infantil e Ensino Fundamental da RME (2020a), com a Base Nacional Comum Curricular (BRASIL, 2017b), com a Carta das Cidades Educadoras (2004) e com os Objetivos de Desenvolvimento Sustentável (2015) (CURITIBA, 2018; CURITIBA, 2019; CURITIBA, 2020).

As propostas lúdicas são para acontecer no entorno das instituições e em diferentes espaços da cidade, por meio de brincadeiras e apreciações culturais, ofertadas pelo programa, em parceria com diferentes segmentos municipais e não governamentais. Dessa forma, contribuem para a garantia dos direitos de aprendizagem e desenvolvimento, entre eles o de “[...] conviver com outras crianças e adultos, em pequenos e grandes grupos, utilizando diferentes linguagens, ampliando o conhecimento de si e do outro, o respeito em relação à cultura e às diferenças entre as pessoas"; e o de brincar "[...] em diferentes espaços e tempos,

\footnotetext{
3 “[...] política de governo refere-se a um plano, um programa ou uma ação desenvolvida para vigorar durante o período de um mandato governamental [...]" (SANTOS, 2012, p. 8).
} 
com diferentes parceiros (crianças e adultos), ampliando e diversificando seu acesso a produções culturais, seus conhecimentos [...]” (BRASIL, 2017b, p. 38).

O professor, principal mediador adulto dessas ações, por meio do programa e da escuta atenta das crianças, tem a oportunidade de enriquecer seus planejamentos, como orienta o artigo $9^{\circ}$ das DCNEI (2009), inciso I, ou seja, garantir por meio de propostas intencionalmente planejadas "[...] o conhecimento de si e do mundo por meio da ampliação de experiências sensoriais, expressivas, corporais que possibilitem movimentação ampla, expressão da individualidade e respeito pelos ritmos e desejos das crianças", bem como, conforme inciso IX, promover " $[\ldots]$ o relacionamento e a interação das crianças com diversificadas manifestações de música, artes plásticas e gráficas, cinema, fotografia, dança, teatro, poesia e literatura" (BRASIL, 2009).

No tocante à promoção dessa gama de experiências e na ampliação patrimonial e cultural das crianças, as propostas fomentadas pelo programa atendem aos seis direitos de aprendizagem e desenvolvimento na educação infantil: conviver e brincar, participar, explorar, expressar e se conhecer (BRASIL, 2017b).

As propostas ofertadas pelo Programa Linhas do Conhecimento às crianças da educação infantil podem ser realizadas a pé, no entorno das unidades, em praças, bosques, parques, bibliotecas e faróis do saber do bairro, espaços culturais, entre outras possibilidades, com o uso de transporte e, também, pela modalidade virtual. Tendo em vista a segurança e a organização das atividades, as atividades pedagógicas em espaços da cidade mais distantes da instituição de ensino são destinadas às crianças das turmas de Pré-Único e Pré-II, conforme normativa do programa.

Para a participação no programa, é imprescindível um planejamento atrelado ao currículo e aos demais documentos norteadores, de forma a enriquecer as experiências culturais das crianças. Para tanto, há a necessidade de intencionalidade educativa por parte do professor, a qual

\footnotetext{
Essa intencionalidade consiste na organização e proposição, pelo educador, de experiências que permitam às crianças conhecer a si e ao outro e de conhecer e compreender as relações com a natureza, com a cultura e com a produção científica, que se traduzem nas práticas de cuidados pessoais [...], nas brincadeiras, nas experimentações com materiais variados, na aproximação com a literatura e no encontro com as pessoas (BRASIL, 2017b, p. 39).
} 
Com efeito, cabe ao educador do presente ouvir novas vozes e celebrar novos vínculos com a sociedade, aqui destacadas as vozes da comunidade que ecoam as vozes da cidade. Nesse sentido, em face da importância das relações entre a educação e a cidade, recorremos às três dimensões propostas por Bernet (1997): aprender na cidade; aprender com a cidade e aprender a cidade.

Nessa perspectiva, correlacionamos o Programa Linhas do Conhecimento com essas dimensões apresentadas por Bernet (1997), isto é, aprender na cidade como a série de acontecimentos educativos realizados por meio das rotas oferecidas em espaços centralizados e descentralizados da cidade para o desenvolvimento das propostas lúdicas e de ampliação cultural. “[...] cuanto más densa seala trama de recursos formativos y de aprendizaje que se ofrecen, tanto más educadora será la ciudad" (BERNET, 1997, p. 22).

Sobre aprender com a cidade, Bernet (1997) considera que a cidade informalmente ensina, por meio das relações e interações, dos conteúdos expostos nas paredes, murais, outdoors, organização dos espaços, cuidado com as ruas e demais espaços urbanos. "Una ciudad que se quiera asumir como verdadera y positivamente educadora debe, en primer lugar, tratar de elucidar este curriculum implícito" (BERNET, 1997, p. 29).

E, por fim, correlacionamos o Programa Linhas do Conhecimento com a dimensão aprender a cidade (BERNET, 1997), pois como esse autor explica, essa aprendizagem implica ampliar as possibilidades de experiências diretas das crianças com e sobre a cidade. Quanto a esse aspecto, destacamos as possibilidades que o Programa Linhas do Conhecimento oferece, qual seja, o de aprender a e na cidade, nos espaços mais próximos e distantes das instituições, bem como por meio da produção de recursos pedagógicos que se materializem em revistas, livretos, vídeos veiculados no site do programa e no YouTube e Tour virtual destinados aos professores, às criança, aos estudantes e à comunidade.

\section{Aproximações entre narrativas e representações sociais}


$\mathrm{Na}$ tessitura em aproximar narrativas e representações sociais, apoiadas em Souza (2011, p. 213), compartilhamos sua compreensão, quando afirma:

Vida e profissão estão imbricadas e marcadas por diferentes narrativas biográficas e autobiográficas, as quais demarcam um espaço onde o sujeito, ao selecionar lembranças da sua existência e ao tratá-las na perspectiva oral e/ou escrita, organiza suas ideias, potencializa a reconstrução de sua vivência pessoal e profissional de forma autorreflexiva e gera suporte para compreensão de suas experiências formativas.

Considerando que as representações sociais resultam da comunicação e da interação (MOSCOVICI, 2015) e constituem uma forma de compreensão sobre a realidade/experiência vivida e os meios de ação sobre ela, porquanto imbrincadas nas esferas de pertença do subjetivo, intersubjetivo e transubjetivo (JODELET, 2009) é que situamos esse movimento de articulação entre a abordagem (auto)biográfica e a Teoria das Representações em um caminho potencial a ser considerado, pois apoiadas em Teibel e Andrade (2017, p. 90), parafraseando Jovchelovitch $\left(2002^{4}\right)$, as “" [... narrativas são uma das principais formas de discurso por meio das quais as representações sociais são atualizadas e ganham vida, encontrando nelas algo parecido como um terrenos privilegiados para se incubar e desenvolver".

A particularidade que envolve o universo cultural de vivências, valores e crenças “[...] inerentes ao grupo social a que pertencemos" (GALVÃO, 2005, p. 328) permite-nos tomar as representações para "[...] decodificar e interpretar as situações que vivemos” (p. 328). Reforça a nossa opção se partirmos do que Jodelet (2005, p. 29) entende por experiência vivida, sendo

[...] o modo através do qual as pessoas sentem uma situação, em seu foro íntimo, e o modo como elas elaboram, através de um trabalho psíquico e cognitivo, as ressonâncias positivas ou negativas dessa situação e as relações e ações que elas desenvolveram naquela situação

Nesse sentido, as RS presentes nas narrativas dos discursos documentais, produzidas por meio de experiências, equivalem a uma construção de determinado grupo, situado em um contexto de interações sociais que corresponde ao seu grupo de pertença, aos outros grupos e ao contexto social. A esse respeito, Jodelet (2005,

\footnotetext{
${ }^{4}$ Jovchelovitch, S. Social representations and narrative: stories of public life in Brazil. In: J. LÁSZLÓ \& W. S. ROGERS. Narrative approaches in Social Psychology (pp. 47-58). Budapeste: New Mandate, 2002.
} 
p. 48) afirma que "[...] a noção de experiência e de vivido nos permite passar do coletivo ao singular, do social ao individual, sem perder de vista o lugar que cabe às representações sociais".

Ao destacar que o processo de construção de narrativas, sejam elas escritas ou faladas, constituem o processo social e cultural de um grupo, Moscovici (2015, p. 154) argumenta que o estudo dos processos culturais

[...] são responsáveis pela organização do conhecimento em uma sociedade, pelo estabelecimento das relações interindividuais no contexto do ambiente social e físico, pela formação dos movimentos sociais (grupos, partidos, instituições) através dos quais os homens agem e interagem, pela codificação da conduta interindividual e intergrupal que cria uma realidade social comum com suas normas e valores, cuja origem deve ser novamente buscada no contexto social.

Dessa forma, apoiamo-nos em Teibel e Andrade (2017, p. 92) ao expor que a RS “[...] como um fenômeno associado à construção narrativa possibilita compreender a relação existente entre o mundo de vida nos quais as pessoas habitam e o processo de elaboração dos estados variáveis desse mundo que se torna inteligível e manejável".

Nessa direção, vislumbramos que tal aproximação oportuniza a compreensão por meio das subjetividades das narrativas dos documentos analisados nesta investigação, aspectos que revelam processos psicossociais que caracterizam a intervenção pedagógica proporcionada pelo Programa Linhas do Conhecimento, tendo em vista que “[...] uma intervenção vincula-se ao desejo de mudar o estado do campo de atuação e transformação de práticas” (JODELET, 2007, p. 52).

\section{Percurso Metodológico}

O caminho traçado para a presente pesquisa constituiu-se em fazer uma análise do discurso do documento "Carta das Cidades Educadoras", produzido pela AICE (2004), alicerçada nas narrativas do caderno do Programa Linhas do Conhecimento da SME/Curitiba e a BNCC da Educação Infantil. Afirmamos que o intuito dessa pesquisa não se baseia na construção de uma análise crítica discursiva, mas sim em refletir acerca das práticas discursivas que se estabelecem entre os documentos e as representações sociais neles imbricadas. Além disso, cabe salientar que apesar das múltiplas possibilidades que as diferentes leituras dos documentos 
possibilitam, esses “[...] mostram um nível mais profundo [...] que se relaciona com a maneira de perceber, de sentir e de pensar o conjunto da realidade social" (WINDISCH, 2001, p. 140).

A análise do discurso permite conceber fenômenos do objeto/sujeito a ser estudado. De acordo com Fairclough (2001, p. 32), utilizaremos a palavra discurso como referência ao "[...] uso da linguagem falada ou escrita [...] sinalizando um desejo de investigá-lo [...] como forma de prática social”.

Ao buscar a análise discursiva documental, surgem possibilidades de compreensão de fenômenos a partir do próprio discurso, pois, de acordo com Moraes (2003, p. 192), uma análise textual “[...] pode ser compreendida como um processo auto-organizado de construção de compreensão em que novos entendimentos emergem de uma sequência recursiva". Assim, é concebível que novos significados do documento sejam estruturados, quando confrontados com as narrativas dos outros documentos apresentados nesse estudo.

Inicialmente, foi realizada a análise de Classificação Hierárquica Descendente (CHD) da Carta das Cidades Educadoras, documento da AICE e, em seguida, foi discutida a relação entre a CHD e as narrativas oriundas do caderno do Programa Linhas do Conhecimento e da BNCC da Educação Infantil, a fim de explorar a análise discursiva entre os três documentos.

Foi organizado um corpus com o texto integral da Carta das Cidades Educadoras, produzida pela AICE e processado no software Iramuteq (Interface de R pourles Analyses Multidimensionnelles de Textes et de Questionnaires), desenvolvido por Ratinaud (2009), possibilitando a análise de CHD. Para Camargo e Schösser (2019, p. 108), “[...] esta forma de classificação apresenta contextos lexicais, que se associam ou não a variáveis descritivas dos produtores do material, sendo indicativos de elementos de uma RS ou de diferentes RS”.

O contexto delineado pelo software Iramuteq teve um aproveitamento de 59 segmentos de textos $(76,72 \%)$ do texto da Carta das Cidades Educadoras, a partir do total de 77 segmentos de texto (ST), dividindo o documento em seis classes que serão o suporte da discussão dos dados apresentados. 


\section{A relação entre os documentos: analisando as representações sociais por meio de narrativas}

A CHD apresentada neste estudo teve como corpus o texto da Carta das Cidades Educadoras (AICE, 2004). Por meio do dendograma, ${ }^{5}$ foi possível perceber a relação do discurso do documento com as perspectivas narradas, presentes no discurso da BNCC e do Caderno do Programa Linhas do Conhecimento, na construção de representações sobre Cidade Educadora. O dendograma apresenta a divisão hierárquica que o corpus sofreu na organização dos dados. A primeira partição (bloco A) separou as classes 1, 2, 3 e 4 das classes 5 e 6 (bloco B). A segunda partição proporcionou a oposição das classes 1 e 2 (bloco A1) das classes 3 e 4 (bloco A2).

Figura 1 - Dendograma: Carta das Cidades Educadoras

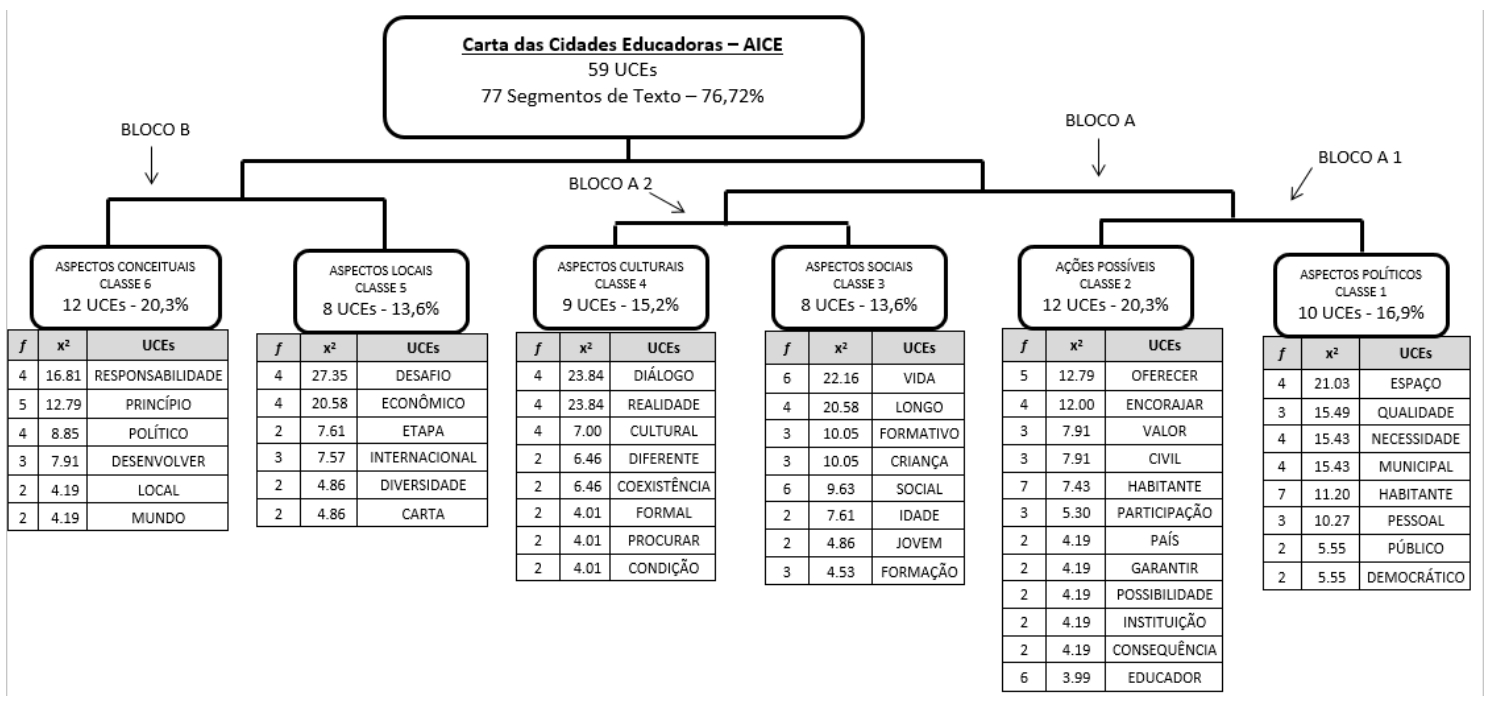

Fonte: as autoras (2020), com base no software Iramuteq (RATINAUD, 2009).

A primeira separação das classes divide o dendograma em dois blocos: Bloco A (classes 1, 2, 3, 4) e Bloco B (classes 5 e 6), representado entre a oposição das classes 1, 2, 3 e 4 com as classes 5 e 6, distinguindo os aspectos políticos (classe 1), sociais (classe 3) e culturais (classe 4), assim como as ações possíveis (classe 2) dos aspectos locais (classe 5) e dos aspectos conceituais (classe 6). A segunda separação das classes abrange o Bloco A, dissociando os aspectos políticos (classe 1) e as ações

\footnotetext{
${ }^{5}$ Para fins de ilustração, foram retidas no dendograma as palavras com associação significativa mais forte para cada classe, medida pelo qui-quadrado.
} 
possíveis (classe 2), denominados de Bloco A1, dos aspectos sociais (classe 3) e culturais (classe 4), denominado de Bloco A2.

O Bloco A abrange os aspectos políticos, as ações possíveis, os aspectos sociais e os aspectos culturais. As classes conversam com os diferentes aspectos que perpassam todo o documento, em consonância com o que Faria (1997, p. 142) assinala:

[...] a cidade que educa tem que ser plenamente responsável por prover as condições externas do educar; se não pode fazer todas iguais e sequer educar a todos por igual, deve ser patrocinadora de igualdade de direitos e oportunidades, de respeito à liberdade de ideias e convicções, de exercício da ação política, de acesso aos bens públicos e à dignidade humana em todos os sentidos.

Ao analisar as classes que constituem o Bloco A1, relacionamos os aspectos políticos à efetivação de ações que o texto do documento interliga. O documento apresenta que "[...] os responsáveis pela política municipal duma cidade deverão possuir uma informação precisa sobre a situação e as necessidades dos seus habitantes" (AICE, 2004), possibilitando, assim, o que chama de consolidação da "plena cidadania democrática". No âmbito municipal, a Lei no 15.335/2018, sancionada no dia 22 de novembro de 2018, autoriza ao município de Curitiba a integrar a AICE e designa como órgão responsável pelo processo de integração e participação a Secretaria Municipal de Educação (SME) do município. Dessa forma, é assumido o compromisso pela busca e consolidação da cidadania, conforme o $\operatorname{artigo} 1^{\circ}$ :

Art. $1^{\circ}$ Fica o Município de Curitiba autorizado a integrar a Associação Internacional de Cidades Educadoras - AICE, que tem como objetivo trabalhar de forma conjunta em projetos e atividades que buscam a melhoria da qualidade de vida dos habitantes (CURITIBA, 2018a - grifos nossos).

A relação estabelecida entre os aspectos políticos e as ações possíveis é evidenciada por Gadotti (2006, p. 136) quando destaca que "[...] precisamos de vontade política e de uma perspectiva histórica", que considere a trajetória histórica da cidade. Nessa perspectiva, o Programa Linhas do Conhecimento é um programa de governo, cujo objetivo, elucidado no Caderno do Programa Linhas do Conhecimento, é 
[...] fortalecer a consciência urbana, a sustentabilidade, a pertença dos sujeitos aos espaços da cidade e a identidade cidadã, envolvendo professores(as) e estudantes em práticas de exploração e conhecimento de Curitiba, considerando três pilares fundamentais: conhecer, amar e cuidar da cidade (CURITIBA, 2018b, p. 11-12).

O processo de formação integral perpassa pela constituição da identidade cidadã e o sentimento de pertença cultural ao grupo. A respeito da Educação Infantil, o Caderno do Programa Linhas do Conhecimento apresenta

No contexto da educação infantil, as atividades têm como ponto de partida as propostas lúdicas, que contribuem para a ampliação cultural a partir do currículo, para as interlocuções sociais e para as práticas pedagógicas dos professores, na intenção de promover a pertença dos sujeitos aos espaços urbanos (CURITIBA, 2018b, p. 12-13).

O Bloco A2 apresenta a relação clara entre os aspectos sociais (classe 3) e os aspectos culturais (classe 4). A perspectiva de uma cidade educadora traz, em sua essência, a formação integral do sujeito. A carta das Cidades Educadoras (AICE, 2004) destaca que

[...] o direito a uma cidade educadora é proposto como uma extensão do direito fundamental de todos os indivíduos à educação. A cidade educadora renova permanentemente o seu compromisso em formar nos aspectos os mais diversos os seus habitantes ao longo da vida.

A garantia desse direito perpassa pelo processo de formação que tenha como base o diálogo e a realidade dos habitantes. Pensando nesse processo, o documento argumenta que

[...] as cidades educadoras com suas instituições educativas formais suas intervenções não formais (de uma intencionalidade educadora para além da educação formal) e informais (não intencionais ou planificadas) deverão colaborar bilateral ou multilateralmente tornando realidade a troca de experiências (AICE, 2004).

\section{A BNCC destaca, em seu texto, que}

$\mathrm{Na}$ Educação Infantil, é importante promover experiências nas quais as crianças possam falar e ouvir, potencializando sua participação na cultura oral, pois é na escuta de histórias, na participação em conversas, nas descrições, nas narrativas elaboradas individualmente ou em grupo e nas implicações com as múltiplas linguagens que a criança se constitui ativamente como sujeito singular e pertencente a um grupo social (BRASIL, 2017b, p. 42).

Destacamos, aqui, a relação entre a troca de experiência e o processo de construção das representações sociais, pois, por mais que as narrativas dos documentos estejam ancoradas em representações do grupo que os produziram, recorremos a Windisch (2001, p. 145) para elucidar que “[...] as representações 
sociais não têm caráter estático que, às vezes, lhes foi atribuído; elas são fundamentalmente móveis, dinâmicas, vivem, atraem-se, repelem-se e geram novas representações".

As classes denominadas de aspectos locais e aspectos conceituais embasam a relação entre o agir local e a ação global. Ao refletir acerca dos aspectos locais, destacamos os desafios no discurso do documento, pois a cidade se faz educativa de acordo com Freire (2001, p. 13)

[...] pela necessidade de conhecer, de criar, de sonhar, de imaginar, que todos nós, mulheres e homens, impregnamos seus campos, suas montanhas, seus vales, seus rios, impregnamos suas casas, seus edifícios, deixando em tudo um selo de certo tempo, o estilo, o gosto de certa época.

O desafio proposto, que depende da vontade do cidadão, é o de compreender como a diversidade $\mathrm{e}$ as necessidades da cidade instauram um ambiente educativo. Ao relacionar com os aspectos conceituais, compreendemos que a visão do todo, respeitando a diversidade, o tempo e o espaço, é extremamente necessária para que a cidade seja educadora, conforme elucida o documento da AICE (2004): “[...] a cidade deverá promover a educação na diversidade para a compreensão a cooperação solidária internacional e a paz no mundo uma educação que deverá combater toda a forma de discriminação".

Nesse contexto, a BNCC corrobora sobre os fenômenos naturais e sociais, considerando a visão do todo, na qual

As crianças vivem inseridas em espaços e tempos de diferentes dimensões, em um mundo constituído de fenômenos naturais e socioculturais. Desde muito pequenas, elas procuram se situar em diversos espaços (rua, bairro, cidade etc.) e tempos (dia e noite; hoje, ontem e amanhã etc.) (BRASIL, 2017b, p. 42).

Perceber a vivacidade do documento no texto dos demais documentos que foram aporte para o presente estudo vai ao encontro do que Gadotti diz: "[...] precisamos de uma pedagogia da cidade para nos ensinar a olhar, a descobrir a cidade, para poder aprender com ela, dela, aprender a conviver com ela" (2006, p. 139).

\section{Para refletir...}


No contexto de pesquisa das representações sociais, refletindo acerca do argumento de Jodelet (2001, p. 26), no qual as

[...] representações sociais devem ser estudadas articulando-se elementos afetivos, mentais e sociais e integrando - ao lado da cognição, da linguagem e da comunicação - a consideração das relações sociais que afetam as representações e a realidade material, social e ideativa sobre a qual elas têm de intervir.

A relação entre o discurso dos documentos analisados, explicitada neste artigo por meio de narrativas — tanto do documento intitulado "Carta das Cidades Educadoras", quanto da BNCC - Educação Infantil e do Caderno do Programa Linhas do Conhecimento - expõe o encontro de ideias e perspectivas sobre o tema "Cidade Educadora”.

As tensões que são causadas pelo processo de aplicação de um documento na prática docente, muitas vezes pela verticalidade do sistema ou determinação, surgem na vivacidade das representações sociais do grupo em questão. Ao analisar o discurso do documento em conformidade com as narrativas presentes nos demais documentos, observamos que o papel político e social do documento se efetiva ao considerar que as narrativas estão ancoradas em princípios enaltecidos no discurso do documento.

Merecem destaque ainda as reflexões que o documento propõe ao colocar questões subjetivas que envolvem os aspectos locais e conceituais, estabelecendo o processo de interpretação e aplicação destas questões em prática. Nesse estudo, o foco foram documentos que orientam o trabalho pedagógico na educação infantil que, na prática, estão pautados e presentes num ambiente naturalmente educativo: os centros municipais de educação infantil. A acolhida do documento na prática docente neste ambiente torna-se viável, uma vez que existe um processo formativo consolidado que possibilita este encontro.

No entanto, o grande desafio é que o discurso do documento vai além dos ambientes culturalmente considerados educativos, pois este coloca que a cidade é o ambiente educativo. É preciso sensibilizar os habitantes da cidade para que o olhar de todos seja voltado ao processo educacional que existe e acontece na cidade. 


\section{Referências}

AICE. Carta das Cidades Educadoras. In: Associação Internacional das Cidades educadoras, 2004. Disponível em: http://www.edcities.org/pt/carta-das-cidades-educadoras/. Acesso em: 27 set. 2019.

ALVES, A. R.; BRANDENBURG, E. J. Cidades educadoras: um olhar acerca da cidade que educa. Curitiba: InterSaberes, 2018.

BALL, S. J.; MAGUIRE, M.; BRAUN, A. Como as escolas fazem as politicas. Trad. Janete Bridon. Ponta Grossa: Editora UEPG, 2016.

BELLOT, P. F. Cidades educadoras, uma aposta de futuro. In: AICE - Associação Internacional das Cidades Educadoras. Educação e vida urbana: 20 anos de Cidades Educadoras. Lisboa: Gráfica Almondina (Torres Novas, Portugal), 2013. p. 17-22. Disponível em: http://www.edcities.org/wp-content/uploads/2015/11/livro-20-anoscidades-educadoras-PT.pdf. Acesso em: 16 mar. 2020.

BERNET, J. T. Ciudades educadoras: bases conceituais. In: ZAINKO, M. A. S.; SCHWARTZ, A. et al. Cidades Educadoras. Curitiba: Ed. da UFPR, 1997. p. 13-34.

BRASIL. Presidência da República. Lei n. ${ }^{\circ}$ 9.394, de 20 de dezembro de 1996. Estabelece as diretrizes e bases da educação nacional. Diário Oficial da União, Brasilia, DF, 23 dez. 1996. Disponível em: http://www.planalto.gov.br/ccivil_03/leis/19394.htm. Acesso em: 07 jun. 2019.

BRASIL. Ministério da Educação. Secretaria de Educação Básica. Parâmetros nacionais de qualidade para a educação infantil. Ministério da Educação. Brasília. DF: MEC, 2006.

BRASIL. Ministério da Educação. Conselho Nacional da Educação. Câmara de Educação Básica. Resolução CNE/CEB, n. ${ }^{\circ}$ 5, de 17 de dezembro de 2009. Fixa as Diretrizes Curriculares Nacionais para a Educação Infantil. Diário Oficial da União, Brasília, DF, 18 dez. 2009. Disponível em: http://portal.mec.gov.br/programa-curriculo-em-movimentosp-1312968422/legislacao. Acesso em: 01 jun. 2019.

BRASIL. Ministério da Educação. Conselho Nacional de Educação. Conselho Pleno. Resolução CNE/CP, no 2, de 22 de dezembro de 2017. Institui e orienta a implantação da Base Nacional Comum Curricular, a ser respeitada obrigatoriamente ao longo das etapas e respectivas modalidades no âmbito da Educação Básica. Diário Oficial da União, Brasilia, DF, 22 dez. 2017a, Seção 1, p. 41 a 44. Disponível em: http://basenacionalcomum.mec.gov.br/images/historico/RESOLUCAOCNE_CP222DE DEZEMBRODE2017.pdf. Acesso em: 13 jan. 2020.

BRASIL. Ministério da Educação. Base Nacional Comum Curricular (BNCC). Educação é a Base. Brasília, DF: MEC/CONSED/UNDIME, 2017b. Disponível em: http://basenacionalcomum.mec.gov.br/. Acesso em: 21 mar. 2020.

CARBONELL, J. A aventura de inovar: a mudança na escola. Trad. Fátima Murad. Porto Alegre: Artmed, 2002. 
CARBONELL, J. Pedagogias do século XXI: bases para a inovação educativa. Porto Alegre: Penso, 2016.

CURITIBA. Lei n. ${ }^{\circ} 15.335$ de 22 de outubro de 2018. Autoriza o Município de Curitiba a integrar a Associação Internacional de Cidades Educadoras - AICE. Diário Oficial do Município de Curitiba. 2018a.

CURITIBA. Prefeitura Municipal de Curitiba. Secretaria Municipal da Educação. Linhas do Conhecimento. 2018b. Disponível em: educacao.curitiba.pr.gov.br/2019/9/pdf/00242149.pdf. Acesso em: 26 out. 2019.

CURITIBA. Prefeitura Municipal de Curitiba. Secretaria Municipal da Educação. Superintendência de Gestão Escolar. Departamento de Desenvolvimento Profissional. Curitiba cidade educadora: Linhas do conhecimento. 2019. Disponível em: https://mideducacao.curitiba.pr.gov.br/2019/12/pdf/00260277.pdf. Acesso em: 24 maio 2020.

CURITIBA. Prefeitura Municipal de Curitiba. Relatório de Plano de Ação - SME. Curitiba, 2018c. Disponível em:

http://multimidia.transparencia.curitiba.pr.gov.br/PlanoGoverno/PlanoAcao/relatorioplano-de-acao-site-viva-curitiba-cidada-2205.pdf. Acesso em: 24 maio 2020.

CURITIBA. Secretaria Municipal da Educação. Linhas do Conhecimento. 2020. Disponível em: https://educacao.curitiba.pr.gov.br/conteudo/linhas-doconhecimento/8267. Acesso em: 24 maio 2020.

FAIRCLOUGH, N. A análise crítica do discurso e a mercantilização do discurso público: as universidades. In: MAGALHÃES, C. (org.). Reflexões sobre a análise crítica do discurso. Belo Horizonte: Faculdade de Letras, UFMG, 2001. p. 31-82.

FARIA, J. H. de. Ser da cidade um eterno aprendiz. In: ZAINKO, M. A. S. et al. Cidades Educadoras. Curitiba: Editora da UFPR, 1997. p. 141-144.

FREIRE, P. A educação na cidade. São Paulo: Cortez, 1991.

FREIRE, P. Politica e educação: ensaios. 5. ed. São Paulo: Cortez, 2001.

GADOTTI, M. A escola na cidade que educa. Cadernos Cenpec, São Paulo, Nova série, [S. 1.], v. 1, n. 1 p. 133-139, maio 2006. Disponível em: http://cadernos.cenpec.org.br/cadernos/index.php/cadernos/article/view/160. Acesso em: 22 mar. 2020.

GALVÃO, C. Narrativas em educação. Ciência \& Educação, Bauru, v. 11, n. 2, p. 327-345, 2005.

JODELET, D. O movimento de retorno ao sujeito e a abordagem das representações sociais. Sociedade \& Estado, Brasília, v. 24, n. 3, p. 679-712, set./dez. 2009. Disponível em: https://www.scielo.br/pdf/se/v24n3/04.pdf. Acesso em: 02 maio 2020.

JODELET, D. Imbricações entre representações sociais e intervenção. In: MOREIRA, A. S. P.; CAMARGO B. V. (org.). Contribuições para teoria e o método de estudos das representacões sociais. João Pessoa: Editora Universitária da UFPB, 2007. p. 45-74. 
JODELET, D. Experiência e representações sociais. In: MENIN, M. S. S.; SHIMIZU, A. M. (org.). Experiência e representação social: questões teóricas e metodológicas. São Paulo: Casa do Psicólogo, 2005. p. 23-56.

JODELET, D. Representações sociais: um domínio em expansão. In: JODELET, D. (org.). As representacões sociais. Rio de Janeiro: Ed. UERJ, 2001. p. 17-44.

JOVCHELOVITCH, S. Social representations and narrative: stories of public life in Brazil. In: LÁSZLÓ J.; ROGERS, W. S. Narrative approaches in Social Psychology. Budapeste: New Mandate, 2002. p. 47-58.

LEFEBVRE, H. O direito à cidade. Trad. Rubens Eduardo Frias. São Paulo: Centauro, 2001.

MOLL, J. A cidade e os seus caminhos educativos: escola, rua e itinerários juvenis. In: AICE - Associação Internacional das Cidades Educadoras. Educação e vida urbana: 20 anos de Cidades Educadoras. Lisboa: Gráfica Almondina (Torres Novas, Portugal), 2013. p. 213-224. Disponível em: http://www.edcities.org/wp-content/uploads/2015/11/livro20-anos-cidades-educadoras-PT.pdf. Acesso em: 16 mar. 2020.

MORAES, R. Uma tempestade de luz: a compreensão possibilitada pela análise textual discursiva. Ciência \& Educação, Bauru, v. 9 n. 2, p. 191-211, 2003.

MOSCOVICI, S. Representações Sociais: Investigações em psicologia social. Trad. Pedrinho Guareschi. 11. ed. Petrópolis: Vozes, 2015.

NÓVOA, A. Firmar a posição como professor, afirmar a profissão docente. Cadernos de Pesquisa, São Paulo, v. 47, n. 166, p. 1106-1133, out./dez. 2017.

POZO, J. M. O conceito de cidade educadora, hoje. In: AICE - Associação Internacional das Cidades Educadoras. Educação e vida urbana: 20 anos de Cidades Educadoras. Gráfica Almondina (Torres Novas, Portugal), 2013. p. 23-34. Disponível em: http://www.edcities.org/wp-content/uploads/2015/11/livro-20-anos-cidades-educadorasPT.pdf. Acesso em: 16 mar. 2020.

RATINAUD, P. Iramuteq: interface de R pour les analyses multidimensionnelles de textes et de questionnaires [Computer software], 2009. Disponível em: http://www.iramuteq.org. Acesso em: 4 maio 2019.

SANTOS, P. S. M. B. Guia prático da política educacional no Brasil: ações, planos, programas e impactos. São Paulo: Cengage, 2012.

SCHÖSSER, A.; CAMARGO, B. V. Elementos caracterizadores de representações sociais sobre relacionamentos amorosos. Pensando famílias, Porto Alegre, v. 23, n. 2, p. 105-118, 2019.

SOUZA, E. C. Territórios das escritas do eu: pensar a profissão-narrar a vida. Educação, Porto Alegre, v. 34, n. 2, p. 213-220, mai./ago. 2011.

TEIBEL, É. N. H.; ANDRADE, D. B. da S. Intervenção em práticas de cuidado à criança no contexto hospitalar: representações sociais da equipe de saúde. Psicologia e Saber Social, 
Rio de Janeiro, v. 6, n. 1, p. 87-100, 2017. Disponível em: https://www.epublicacoes.uerj.br/index.php/psi-sabersocial/issue/view/1574. Acesso em: 12 maio 2020.

TONUCCI, F. La ciudad de losniños, um modo nuevo de pensar laciudad. In: ZAINKO, M. A. S. et al. Cidades Educadoras, Curitiba: Editora da UFPR, 1997. p. 45-74.

TONUCCI, F. A verdadeira democracia começa aos três anos. Revista Pátio: Educação Infantil, Porto Alegre, ano III, n. 8, p. 16-20, jul./out. 2005.

VYGOTSKY, L. S. A formação social da mente: o desenvolvimento dos processos psicológicos superiores. 4. ed. São Paulo: Martins Fontes, 1991.

WINDISCH, U. Representações Sociais, sociologia e sociolinguística. O exemplo do raciocínio e da fala cotidiana. In: JODELET, D. (org.). As representações sociais. Rio de Janeiro: EdUERJ, 2001. p. 139-151.

ZAINKO, M. A. S. et al. Cidades Educadoras. Curitiba: Editora da UFPR, 1997.

ZITKOSKI, J. Educação e emancipação social: um olhar a partir da cidade educadora. Revista Espaço Pedagógico, Passo Fundo, v. 13, n. 1, p. 9-18, jan./jun. 2006. Disponível em: http://seer.upf.br/index.php/rep/issue/view/615. Acesso em: 21 maio 2020.

RECEBIDO: 01/06/2020

APROVADO: $28 / 07 / 2020$

RECEIVED: 06/01/2020

APPROVED: 07/28/2020

RECIBIDO: 01/06/2020

APROBADO: $28 / 07 / 2020$ 